\title{
Ethnic-Racial Socialization Has an Indirect Effect on Self-Esteem for Asian American Emerging Adults
}

\author{
Carrie M. Brown ${ }^{1}$, Wells Ling ${ }^{2}$ \\ ${ }^{1}$ Department of Psychology, Agnes Scott College, Decatur, Georgia, USA \\ ${ }^{2}$ Department of Psychology, Saint Louis University, St. Louis, Missouri, USA \\ Email: cmbrown@agnesscott.edu
}

Received September $30^{\text {th }}, 2011$; revised November $21^{\text {st }}, 2011$; accepted December $22^{\text {nd }}, 2012$

\begin{abstract}
Although there has been recognition of the importance of examining the indirect effect of perceived parental ethnic-racial socialization on youths' psychosocial outcomes, few studies have done so. To date, Tran and Lee's (2010) study is one of few that has linked ethnic-racial socialization to psychosocial outcomes among Asian Americans, specifically. The purpose of this study was to extend Tran and Lee's (2010) research in two ways. First, the present study tested a model similar to Tran and Lee's but replaced their dependent variable, social competence, with self-esteem. Second, the present study tested the model among Asian American emerging adults (i.e., ages 18 to 25), not late adolescents. The present study hypothesized that perceiving more frequent messages of cultural socialization-pluralism from parents would indirectly lead to higher self-esteem via stronger ethnic identity. One-hundred-fourteen self-identified Asian Americans ( $M$ age $=21.34$ years; $66 \%$ female) completed an online survey that included measures of perceived cultural socialization-pluralism, ethnic identity, and self-esteem. Based on model testing via the bootstrap method (Preacher \& Hayes, 2008), the hypothesis was supported. The findings of the present study contribute to the discussion of the role that perceived ethnic-racial socialization plays in Asian Americans' positive development. Further, the present study contributes to the limited research on ethnicracial socialization among Asian Americans.
\end{abstract}

Keywords: Ethnic-Racial Socialization; Ethnic Identity; Self-Esteem; Asian Americans; Emerging Adults

\section{Introduction}

Socialization is defined as the transmission of attitudes, customs, motives, roles, skills, and values from a range of socialization agents (e.g., parents, teachers, community members) to youths (Harrison, Wilson, Pine, Chan, \& Buriel, 1990; Parke \& Buriel, 1998). Accompanying the growth of ethnic and racial groups in the United States, research over the last 30 years has focused on the socialization processes of ethnic and racial minority families (Quintana et al., 2006). Researchers have revealed that socializing youth about ethnicity and race (i.e., ethnicracial socialization) is a predominant component of socialization in ethnic and racial minority families (Garcia Coll et al., 1996).

Any socialization agent (e.g., teachers) can engage in ethnic-racial socialization with youths (Harrison et al., 1990; Parke \& Buriel, 1998). However, the majority of the extant literature on ethnic-racial socialization has focused on the messages and practices that come from parents. This comes as no surprise, as developmental psychology highlights parents as especially engaged in youths' development (Grusec \& Kuczynski, 1997; Steinberg \& Morris, 2001).

One of the most well-known models of parental ethnic-racial socialization was developed by Hughes and Chen (1997). Hughes and Chen's model consists of four dimensions: 1) cultural socialization (emphasis on pride in one's ethnic or racial group, traditions, and history); 2) pluralism (emphasis on an appreciation and knowledge of all ethnic and racial groups and treating all groups as equal); 3) promotion of mistrust (emphasis on being cautious of other ethnic and racial groups and pushing for maintaining distance from them); and 4) preparation for bias (emphasis on promotion of an awareness of ethnic and racial prejudice and discrimination that occurs in society). Although the model was initially developed for African American families, researchers have found that the model can be applied to families of other ethnic and racial backgrounds (e.g., Hughes, 2003).

Researchers have revealed that parental ethnic-racial socialization (in particular, the dimension of cultural socialization) is connected to ethnic identity among ethnic and racial minority youths (Rivas-Drake, Hughes, \& Way, 2009; Umaña-Taylor, Bhanot, \& Shin, 2006). In a separate line of research, researchers have revealed that ethnic identity is connected to psychosocial outcomes, including higher self-esteem, among ethnic and racial minority youths (see Phinney, 1990, for a review). However, few studies have connected these two lines of research by testing a larger model that links parental ethnic-racial socialization, ethnic identity, and psychosocial outcomes among ethnic and racial minority youths.

To date, Tran and Lee's (2010) study is one of few to examine a larger model that links parental ethnic-racial socialization to psychosocial outcomes among Asian Americans, specifically. According to Tran and Lee (2010), there is a need for research that addresses parental ethnic-racial socialization among Asian Americans, as only a handful of relevant studies have included Asian Americans (Cheng \& Kuo, 2000; Nagata, 1993; Ou \& McAdoo, 1993). Further, Tran and Lee (2010) affirm that there "remains a need for research focusing on the ... developmental correlates of specific ethnic-racial practices within Asian Ame- 
rican families to understand the psychosocial adjustment of Asian Americans" (p. 170). In their study, Tran and Lee (2010) recruited Asian American late adolescents $(N=169)$ and tested a model that proposed that perceived cultural socialization-pluralism (a combination of both cultural socialization and pluralism messages) has an indirect effect on perceived social competence via ethnic identity. The authors found support for the model: When participants reported perceiving more frequent messages of cultural socialization-pluralism from their parents, this had an indirect effect on better social competence via stronger ethnic identity. Tran and Lee (2010) note that more research is needed to "understand ethnic-racial socialization across the life span" (p. 176).

\section{Purpose of Present Study}

The purpose of the present study was to extend Tran and Lee's (2010) research in two ways. First, the present study tested a model similar to Tran and Lee's but replaced their dependent variable, social competence, with self-esteem. We chose to examine self-esteem because: 1) of its connection to ethnic identity (Phinney, 1990), and 2) it is another potential developmental correlate of ethnic-racial socialization that should be considered. Second, the present study tested the model among Asian American emerging adults (i.e., ages 18 to 25), not late adolescents. The present study focused on emerging adulthood because: 1) this a time of new opportunities and experiences which may encourage ethnic identity development, as well as the development of other constructs (Arnett, 2006), and 2) Tran and Lee (2010) note that more research is needed to "understand ethnic-racial socialization across the life span" (p. 176).

The present study hypothesized that perceiving more frequent messages of cultural socialization-pluralism from parents would indirectly lead to higher self-esteem via stronger ethnic identity. See Figure 1.

\section{Method}

\section{Participants}

The participants were 114 self-identified Asian Americans ( $M$ age $=21.34$ years, $S D=1.74$ years; $66 \%$ female). The reported familial countries of origin were China $(26 \%)$, Vietnam (20\%), Philippines (18\%), Taiwan (18\%), Japan (8\%), Hong Kong (6\%), Thailand (2\%), Cambodia (1\%), and Laos (1\%). The majority of the participants $(82 \%)$ reported that they were born in the United States.

\section{Materials}

Demographics. The participants were asked to report their age, gender, familial country of origin, and country of birth.

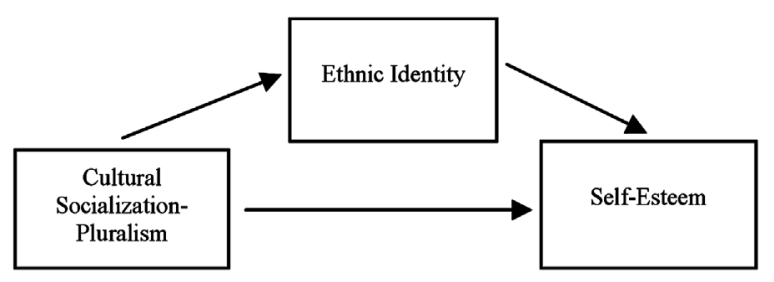

Figure 1.

Proposed model in the present study.
Cultural socialization-pluralism. The participants comple- ted the cultural socialization-pluralism dimension (five items total) from Hughes and Johnson's (2001) measure. In Hughes and Johnson's (2001) measure, the items measured the frequency of parent-reported ethnic-racial socialization over the past year. In our study, there were two differences. First, the items were reported by the participants, not the participants' parents [similar to Tran and Lee's (2010) study]. Second, the items were adapted to measure perceived cultural socialization-pluralism while growing up, not over the past year alone. The participants responded to the five items on a five-point scale ranging from 1 (never) to 5 (very often). Two example items are: "While growing up, how often have your parent(s) done or said things to show you that all people are equal regardless of race/ethnicity?" and "While growing up, how often have your parent(s) encouraged you to read books about your racial/ethnic group?" A higher mean score indicates a perception of more frequent cultural socialization-pluralism. In the present study, the alpha for perceived cultural socialization-pluralism was .78.

Ethnic identity. The participants completed the Multigroup Ethnic Identity Measure (Phinney, 1992). The participants responded to the 12 items on a four-point scale, ranging from 1 (strongly disagree) to 4 (strongly agree). An example item is: "I have a strong sense of belonging to my own ethnic group." A higher mean score indicates a stronger ethnic identity. In the present study, the alpha for ethnic identity was .89.

Self-Esteem. The participants completed the Rosenberg SelfEsteem Scale (Rosenberg, 1965). The participants responded to the 10 items on a four-point scale ranging from 1 (strongly disagree) to 4 (strongly agree). An example item is: "I feel that I have a number of good qualities." A higher mean score indicates higher self-esteem. In the present study, the alpha for selfesteem was .90 .

\section{Procedure}

Before initiating participant recruitment, approval was obtained from the appropriate Institutional Review Board. The participants were recruited via snowball sampling on Facebook (www.facebook.com) and completed an anonymous online survey. All participants were eligible to enter a raffle to win monetary prizes.

\section{Results}

Table 1 provides the correlations, means, and standard deviations of perceived cultural socialization-pluralism, ethnic identity, and self-esteem. Perceived cultural socialization-pluralism was positively correlated with ethnic identity, but not with self-esteem. Ethnic identity was positively correlated with selfesteem. See Table 1.

Table 1.

Correlations and descriptive statistics of study variables.

\begin{tabular}{lcccccc}
\hline \multicolumn{1}{c}{ Scale } & 1 & 2 & 3 & $M$ & $S D$ & $N$ \\
\hline 1. Cultural Socialization-Pluralism & - & $.28^{*}$ & .04 & 2.27 & .76 & 114 \\
2. Ethnic Identity & & - & $.18^{+}$ & 3.01 & .50 & 114 \\
3. Self-Esteem & & & - & 2.98 & .50 & 114
\end{tabular}

${ }^{*} p<.01,{ }_{p}=.05$. 
In order to test the hypothesized model, the bootstrap method was utilized (Preacher \& Hayes, 2008) in SPSS version 19.0. The bootstrap method is a non-parametric statistical approach in which cases from the original data set are randomly re-sampled with replacement, which re-estimates the sampling distribution of the indirect effect (i.e., the $a$ path multiplied by the $b$ path). This re-sampling process is repeated thousands of times (in our study, it was repeated 5,000 times), which creates an estimate of the sampling distribution of the indirect effect. The estimate is presented via confidence intervals. If zero is not contained within the upper and lower confidence intervals, the indirect effect is considered significant. The bootstrap method has advantages over other methods of testing mediation (Shrout \& Bolger, 2002), as it 1) does not compromise statistical power with multiple tests (Baron \& Kenny, 1986); 2) does not hold the assumption of a normal distribution of the data (Sobel, 1982, 1986); and 3) is the preferred approach for small-to-medium sample sizes.

Before testing the hypothesized model, the demographic variables [age, gender, familial country of origin, and country of birth (US or not)] were correlated with the dependent variable, self-esteem. Two of the demographic variables were correlated with higher self-esteem: age $(r=.29, p=.002)$ and male gender $(r=-.20, p=.04)$. Therefore, both age and gender were controlled for in the model testing.

The results of the model testing revealed that the model was significant $(p=.001)$, with an $R^{2}$ value of .15 . Zero was not contained within the upper (.0052) and lower (.0869) confidence intervals of the indirect effect. Therefore, the indirect effect was significant, and the hypothesis was supported: Perceiving more frequent cultural socialization-pluralism from parents indirectly led to higher self-esteem via stronger ethnic identity.

\section{Discussion}

The purpose of the present study was to extend Tran and Lee's (2010) research in two ways. First, Tran and Lee's dependent variable, social competence, was replaced with self-esteem. Second, the model was tested among Asian American emerging adults, not late adolescents. The present study hypothesized that perceiving more frequent messages of cultural socialization-pluralism from parents would indirectly lead to higher self-esteem via stronger ethnic identity. Based on model testing via the bootstrap method (Preacher \& Hayes, 2008), the hypothesis was supported.

The findings of the present study suggest that perceived cultural socialization-pluralism has an indirect effect not only on the psychosocial outcome of social competence (Tran \& Lee, 2010), but on the psychosocial outcome of self-esteem as well. Further, the findings of the present study suggest that the indirect effect of perceived ethnic-racial socialization on psychosocial outcomes may be a phenomenon that is relevant not only for Asian American late adolescents, but also for Asian American emerging adults.

The present study has limitations that must be addressed. First, the data are entirely correlational and, therefore, conclusions about causality cannot be made. Second, there is no perspective from the participants' parents, which prevents capturing a larger picture of the socialization processes within the participants' families. Third, the sample combined Asian American ethnic groups. This is similar to the approach taken by Tran and Lee (2010), as the researchers also combined the Asian Ameri- can ethnic groups in their study. However, in the future, researchers should aim to look at distinct Asian American ethnic groups without aggregation.

The present study contributes to the discussion of the role that perceived ethnic-racial socialization plays in Asian Americans' positive development. Further, the present study contributes to the limited research on ethnic-racial socialization among Asian American families. In the future, researchers might consider looking at the indirect effects of additional ethnic-racial socialization dimensions (e.g., preparation for bias) on psychosocial outcomes beyond social competence and self-esteem. Further, longitudinal studies in this area should be considered.

\section{Acknowledgements}

The authors thank Rachel Cook of Agnes Scott College for her assistance with this paper.

\section{REFERENCES}

Arnett, J. J. (2006). Emerging adulthood: The winding road from the late teens through the twenties. Oxford: Oxford University Press.

Baron, R. M., \& Kenny, D. A. (1986). The moderator-mediator variable distinction in social psychological research: Conceptual, strategic, and statistical considerations. Journal of Personality \& Social Psychology, 51, 1173-1182. doi:10.1037/0022-3514.51.6.1173

Cheng, S. H., \& Kuo, W. H. (2000). Family socialization of ethnic identity among Chinese American pre-adolescents. Journal of Comparative Family Studies, 31, 463-484.

Garcia Coll, C. T., Lamberty, G., Jenkins, R., McAdoo, H. P., Crnic, K., Wasik, B. H., \& Vazquez Garcia, H. (1996). An integrative model for the study of developmental competencies in minority children. Child Development, 67, 1891-1914. doi:10.2307/1131600

Grusec, J. E., \& Kuczynski, L. (1997). Parenting and children's inter nalization of values: A handbook of contemporary theory. New York, NY: Wiley.

Harrison, A. O., Wilson, M. N., Pine, C. J., Chan, S. Q., \& Buriel, R. (1990). Family ecologies of ethnic minority children. Child Development, 61, 347-362. doi:10.2307/1131097

Hughes, D. (2003). Correlates of African American and Latino parents' messages to children about ethnicity and race: A comparative study of racial socialization. American Journal of Community Psychology, 31, 15-33. doi:10.1023/A:1023066418688

Hughes, D., \& Chen, L. (1997). When and what parents tell children about race: An examination of race-related socialization among African American families. Applied Developmental Science, 1, 200-214. doi: $10.1207 / \mathrm{s} 1532480 \mathrm{xads} 01044$

Hughes, D., \& Johnson, D. (2001). Correlates in children's experiences of parents' racial socialization behaviors. Journal of Marriage and Family, 63, 981-995. doi:10.1111/j.1741-3737.2001.00981.x

Nagata, D. K. (1993). Legacy of injustice: Exploring the cross-generational impact of the Japanese American internment. New York, NY: Plenum Press.

Ou, Y. S., \& McAdoo, H. P. (1993). Socialization of Chinese American children. In H. P. McAdoo (Ed.), Family ethnicity: Strength in diversity (pp. 245-270). Thousand Oaks, CA: Sage.

Parke, R. D., \& Buriel, R. (1998). Socialization in the family: Ethnic and ecological perspectives. In N. Eisenberg (Vol. Ed.), \& W. Damon (Series Ed.), Handbook of child psychology: Social, Emotional, and Personality Development. New York, NY: Wiley.

Phinney, J. S. (1990). Ethnic identity in adolescents and adults: Review of research. Psychological Bulletin, 108, 499-514. doi:10.1037/0033-2909.108.3.499

Phinney, J. S. (1992). The Multigroup Ethnic Identity Measure: A newscale for use with diverse groups. Journal of Adolescent Research, 7, 156-176. doi: $10.1177 / 074355489272003$

Preacher, K. J., \& Hayes, A. F. (2008). Asymptotic and resampling strategies for assessing and comparing indirect effects in multiple 


\section{M. BROWN ET AL.}

mediator models. Behavior Research Methods, 40, 879-891.

doi:10.3758/BRM.40.3.879

Quintana, S. M., Aboud, F. E., Chao, R. K., Contreras-Grau, J., Cross, W. E., Jr., Hudley, C., \& Vietze, D. L. (2006). Race, ethnicity, and culture in child development: Contemporary research and future directions. Child Development, 77, 1129-1141. doi:10.1111/j.1467-8624.2006.00951.x

Rivas-Drake, D., Hughes, D., \& Way, N. (2009). A preliminary analysis of associations among ethnic-racial socialization, ethnic discrimination, and ethnic identity among urban sixth graders. Journal of Research on Adolescence, 19, 558-584.

doi:10.1111/j.1532-7795.2009.00607.x

Shrout, P. E., \& Bolger, N. (2002). Mediation in experimental and nonexperimental studies: New procedures and recommendations. Psychological Methods, 7, 422-445. doi:10.1037/1082-989X.7.4.422

Sobel, M. E. (1982). Asymptotic confidence intervals for indirect effects in structural equations models. In S. Leinhart (Ed.), Sociological methodology (pp. 290-312). San Francisco, CA: Jossey-Bass.
Sobel, M. E. (1986). Some new results on indirect effects and their standard errors in covariance structure models. In N. Tuma (Ed.), Sociological methodology (pp. 159-186). Washington DC: American Sociological Association.

Steinberg, L., \& Morris, A. S. (2001). Adolescent development. Annual Review of Psychology, 52, 83-110. doi:10.1146/annurev.psych.52.1.83

Rosenberg, M. (1965). Society and the adolescent self-image. Prince ton, NJ: Princeton University Press.

Tran, A., \& Lee, R. (2010). Perceived ethnic-racial socialization, ethnic identity, and social competence among Asian American late adolescents. Cultural Diversity and Ethnic Minority Psychology, 16, 169178. doi:10.1037/a0016400

Umaña-Taylor, A. J., Bhanot, R., \& Shin, N. (2006). Ethnic identity formation during adolescence: The critical role of families. Journal of Family Issues, 27, 390-414. doi:10.1177/0192513X05282960 